\title{
THE STABILIMENTA OF NEPHILA CLAVIPES AND THE ORIGINS OF STABILIMENTUM-BUILDING IN ARANEIDS*
}

\author{
By Michael H. Robinson and Barbara C. Robinson \\ Smithsonian Tropical Research Institute, \\ P.O. Box 2072, Balboa, Canal Zone
}

Structures of multi-strand (ribbon) silk are built into the webs of certain araneid and uloborid spiders. These devices are widely known as stabilimenta (following Simon I895). Marples (1969) has objected to the functional connotations of the term and has called such structures decorations. However, we feel that there is no point in abandoning a term that has acquired a designatory value largely independent of functional implications.

The stabilimenta built by araneids differ, from species to species, in form, complexity and disposition within the web. There can also be differences between the stabilimenta built by different developmental stages within the same species. Some species build disc stabilimenta at one stage in the life cycle and linear stabilimenta at another (almost always later) stage. Despite these differences (examples in Robinson \& Robinson 1970, Ewer 1972, general discussion with references in Kaston 1964) araneid stabilimenta have constructional features in common. With the exception noted below, all the stabilimenta that have been described consist purely of silk that is laid down between structural elements of the web in a zig-zag manner. In linear stabilimenta, the subject of this paper, the zigzags bridge the gap between adjacent radii. An exception to this common constructional feature occurs in the stabilimenta built by some species of Cyclosa in which the devices incorporate discarded remnants of prey and other debris, and may also contain egg sacs. These stabilimenta are perhaps best regarded as a special case and could be described as 'composite.'

As far as we are aware, there has been no record of stabilimentum building by spiders of the genus Nephila prior to its discovery in Nephila maculata (Fabricius) by Robinson \& Robinson (1973). These authors found that $N$. maculata builds a perpendicular linear stabilimentum in very rare instances. The structure is built only by immature females and shares the constructional features described

*Manuscript received by the editor November 4, 1973. 
Table 1. Results of web census of Nephila maculata (July 1973) at localities in southwest Canal Zone, between Rodman and Arraijan.

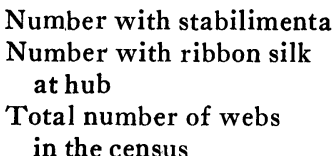

\begin{tabular}{cc}
\multicolumn{2}{c}{ Adults } \\
Perfect & Skeleton \\
0 & 0 \\
52 & 0 \\
65 & 0
\end{tabular}

*Females above $10 \mathrm{~mm}$ in size.

$$
\begin{array}{lr}
\text { \% of all webs with hub silk } & 80.7 \% \\
\text { \% of all webs with stabilimenta } & 4.4 \% \\
\text { \% of skeleton webs with stabilimenta } & 54.5
\end{array}
$$

above. It is of multi-strand silk laid down between adjacent radii (see Robinson \& Robinson 1973, Figure 5).

In this paper we describe examples of stabilimenta built by immature females of Nephila clavipes (L.) and discuss the functional and evolutionary implications of the rare phenomenon of stabilimentum building by Nephila species.

\section{The stabilimenta of Nephila clavipes}

Nephila clavipes is widely distributed in the New World tropics and extends into subtropical regions to the north and south (see Bonnet 1958). Notes on the web structure and ecology of this species appear in studies by Peters (1953, 1954, 1955). In Panama the species is relatively common in most lowland areas where trees and bushes persist. Our preliminary studies of seasonal abundance suggest that it becomes rare towards the end of the dry season (April-May). Populations build up again during the wet season with adults becoming numerous by July-August. We first discovered a stabilimentum in the web of $N$. clavipes in a garden at Rio Indio, Arraijan, Republic of Panama in July 1973. After this discovery we censussed 275 webs of adults and immatures (Table I) in forestedge areas in the southwestern part of the Canal Zone around the Interamerican Highway.

As a result of the census we discovered 12 stabilimenta, all of which were in skeleton webs (see below) of immature females. Thus stabilimenta were present in only $4.4 \%$ of the webs examined. The census included 65 adult webs and 210 webs of immature females. Of the latter 22 were without viscid elements and are referred to as skeleton webs. Fifty-four percent of the skeleton webs 


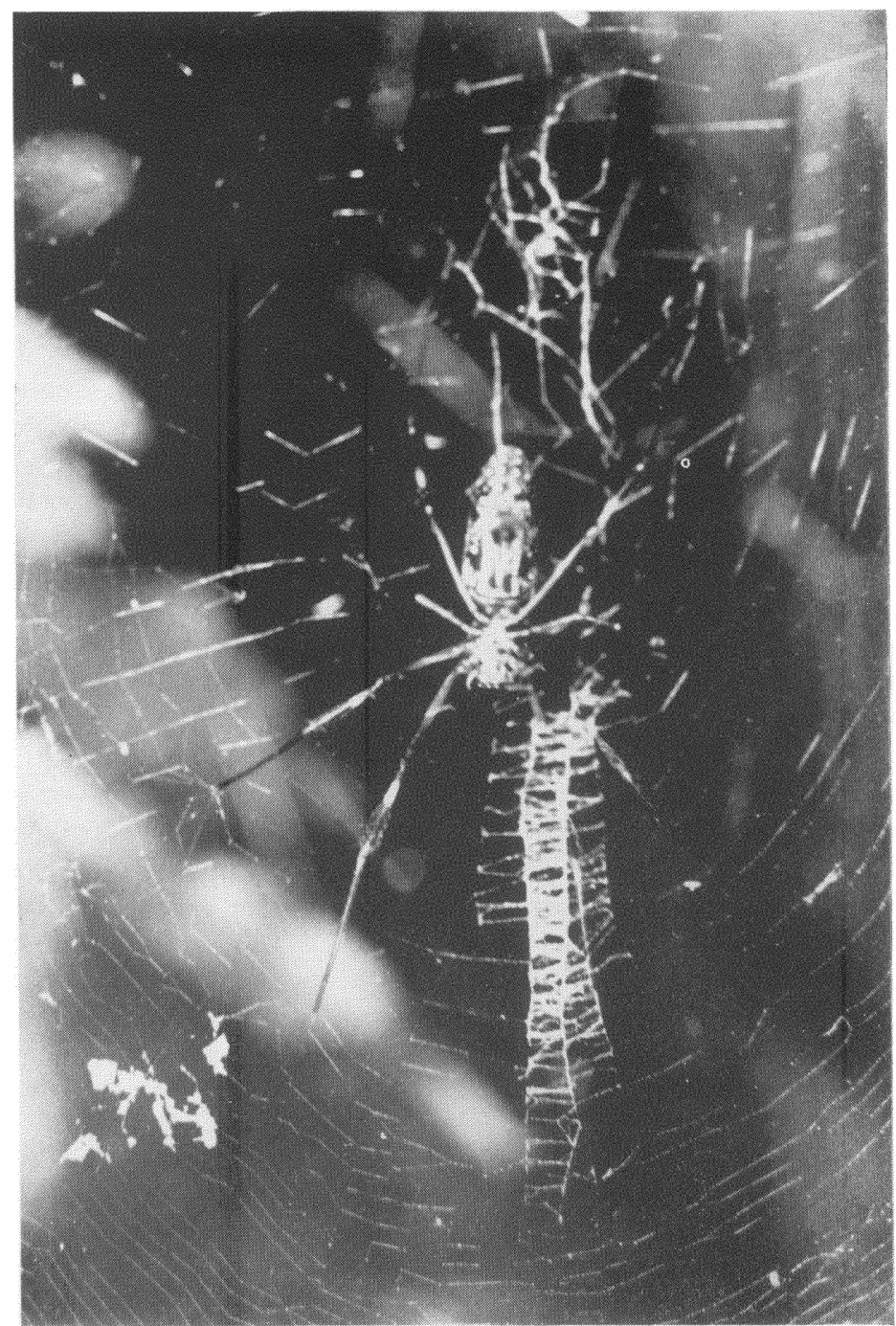

Fig. 1. Stabilimentum in perfect web of juvenile female Nephila clavipes. Dimensions in text. 
contained stabilimenta. The original stabilimentum discovered at Arraijan was in a functional web and differed in detail from those found in skeleton webs. No stabilimenta of this type were encountered during the census. We photographed the first-found stabilimentum and one of the type found in skeleton webs and also collected several of the latter on black paper to analyse in detail. The accompanying photographs were made without coating the web to enhance its visibility since this could have obscured the detail of the stabilimenta by rendering structural members differentially more conspicuous than in the natural state. Web photography was accomplished by using two flash units, one placed at right angles to the web and one discharging along the plane of the web from below.

Figure I shows the stabilimentum in the complete web. The immature female was ca. $17 \mathrm{~mm}$ in length and occupied a web approximately $29 \mathrm{~cm}$ in height (between upper and lower foundation threads). The web was in a shaded location surrounded by bushes and had a dense and complex barrier web dorsal to the spider (below the sloping main sheet) and a second less dense barrier web above the web, ventral to the spider. The zig-zags of stabilimentum silk were laid down across three inter-radial gaps and in the lower part also followed a branched radius, but were mainly concentrated between two radii. The whole structure, of golden ribbon silk, formed a somewhat imperfect perpendicular stabilimentum, quite dense over $22 \mathrm{~mm}$ of its length, and about $33 \mathrm{~mm}$ in total length. As can be seen from the figure, the stabilimentum extended from the hub region into the viscid spiral zone.

The stabilimenta found in skeleton webs all consisted of much longer structures in which silk was deposited between much more widely spaced radii with the attachment points more widely dispersed on the structural elements. Figure 2 shows a section of one such stabilimentum in which stabilimentum silk was deposited entirely on a single radius for part of the length of the structure. All these stabilimenta were relatively inconspicuous and could have been overlooked in casual examination of the webs. One skeleton web stabilimentum that we collected had zig-zags of multi-strand silk extending over seven inter-radial spaces and was $30 \mathrm{~mm}$ wide (maximum) and over $75 \mathrm{~mm}$ long.

The structure and function of skeleton webs

Several species of araneid spiders that we have studied cease to build complete webs at some stage and rest for one or more days on skeleton webs. We noted this phenomenon, without explanation, in 


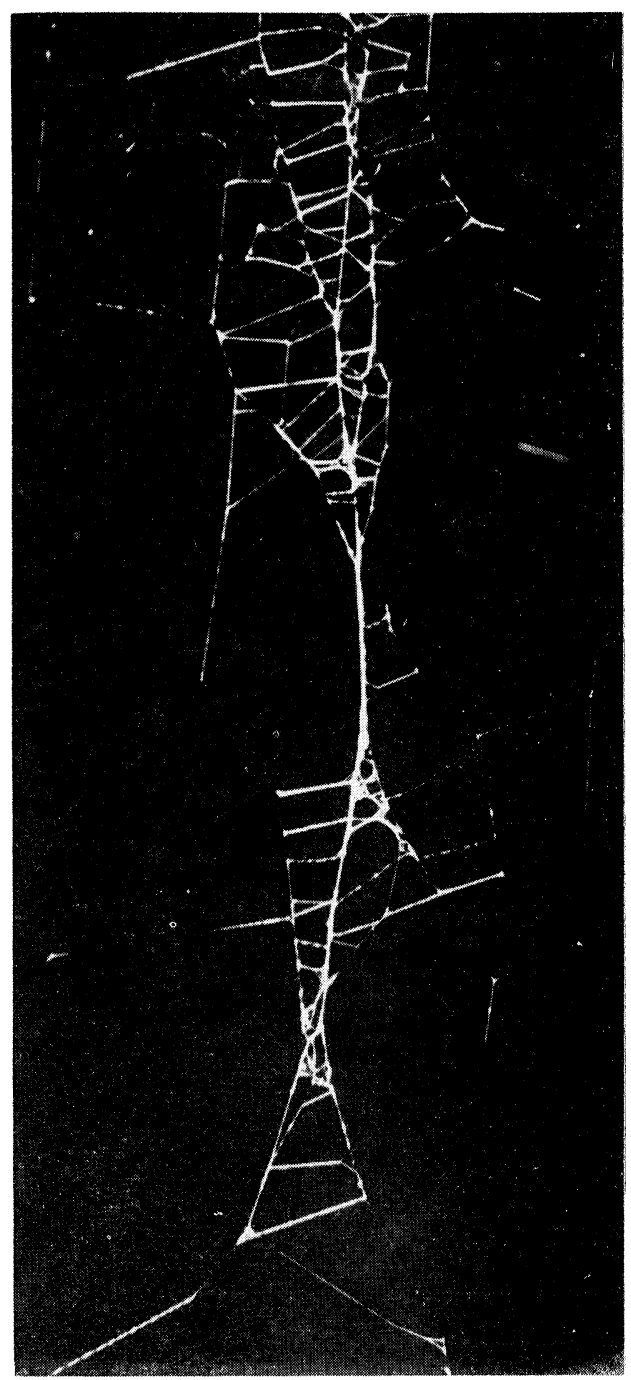

Fig. 2. Part of stabilimentum (ca. $8.5 \mathrm{~mm}$ long) from skeleton web of N. clavipes. 
the case of Argiope argentata (Fabricius) during a study involving the examination of 26I4 adult webs of this species (Robinson \& Robinson 1970: 644). Examination of our unpublished data on the nature of skeleton webs shows that they were not simply old webs but constructions with a small number of radii, no viscid spiral and no well-defined structural spiral. Stabilimenta in such webs were extremely long, had widely spaced zig-zags and frequently had areas where the stabilimentum silk was deposited on top of a single radius. Thus the constructional details of these stabilimenta were strikingly parallel to those seen in the stabilimenta found in skeleton webs of $N$. clavipes. This can be seen by comparing Figure 2 herein with Figure 3 of Robinson \& Robinson (I970: 646). In our study of Nephila maculata we found adult females ceased web renewal several days before egg-laying but remained on old, or skeleton, webs (Robinson \& Robinson 1973). We now suspect that the examples of skeleton webs that we found in Argiope argentata were constructed by females that were about to lay eggs and that in both cases these webs function as resting platforms at a stage when food capture has become unnecessary. In the case of Nephila clavipes the skeleton webs of immature females almost certainly function as moulting platforms. (We were fortunate to see one female ecdyse whilst on a skeleton web and found two others with cast cuticles still present.) The spider moults below the web, hanging on a silk line attached to its hub. When moulting is complete, the spider eventually swings back onto the skeleton web and assumes a normal predatory stance.

The skeleton webs of Nephila clavipes that we examined (22) were characterized by small area (compared with the perfect webs of the same developmental stage) and the small number of radii that were present. The hub regions appeared to be normal and barrier webs were present in all cases. Strong (thick) bracing threads connected the hub region to one or other of the barrier webs, or sometimes to both of these structures. Such threads are present in most of the webs of Nephila clavipes and produce a conical distortion of the hub above the spider's resting area. In this region there are often deposits of sheet silk laid down irregularly over the hub elements and base of the bracing line(s). Of the 275 webs that we censussed, $80.7 \%$ had conspicuous silk deposits on this region. The significance of this aspect of web structure is discussed below.

\section{Discussion}

Three central (and related) questions result from our study of the stabilimenta of Nephila clavipes and N. maculata: 
I. What is the function of these devices?

2. Why are they built so rarely?

3. Why are they found only in the webs of juveniles?

There have been numerous functional interpretations of the ribbon stabilimenta of araneids. These are briefly summarized in Table 2 and expounded in more detail by Robinson \& Robinson (1970) and Ewer (1972). The assumption that a unitary explanation is necessary for all the structures that are semantically united by being described as stabilimenta is invalid on logical grounds alone, as Robinson \& Robinson (ibid, 654) point out. (It is also important to stress that spiders at different stages in development may be subjected to attacks by different spectra of predators, because of size differences or different web-site preferenda. For this reason juvenile and adult stabilimenta could differ in both mode of operation and overall function.)

In exploring the possible function(s) of Nephila stabilimenta we will treat the two basic forms described above separately. The stabilimenta built in skeleton webs differ strikingly from the single ribbon stabilimentum found in a perfect web. The latter and the rare stabilimenta of Nephila maculata are essentially similar.

We believe that most of the forms of defensive function listed in Table 2 can be securely rejected in the case of the stabilimenta found in skeleton webs, for the reasons set out below:

I. Direct concealment can be rejected because the device does not cover the region where the spider rests.

Table 2. Hypotheses of stabilimentum function (for unattributed sources see Robinson \& Robinson 1970).

Antipredator function

1. Direct concealment of spider (requires that the device covers the spider)

2. Disguise (requires that the device appears continuous with the body or legs of the spider)

3. Deflection (requires that the predator attacks the device rather than the spider)

4. Advertisement (requires that the predator seeks to avoid the web that is advertised by the device)

5. Shielding (requires that the device strengthens the hub against penetration by predators)

\section{Mechanical function}

1. The device in some way allows the spider to adjust the state of the completed web after it has applied its own weight to the hub region.

Other functions

1. The device acts as a visual attraction to insects (Ewer 1972)

2. The device protects the web against damage by large insects (which the spider could not subdue) by making it conspicuous (Ewer 1972)

3. The device acts as a sunshield thereby eliminating the need for costly postural thermoregulation. 
2. Disguise can be rejected because the structure is by no means conspicuous and, in any case, is separated from the spider by a wide gap.

3. Deflection can be rejected because of this same lack of conspicuousness (resulting from the wide dispersal of the opaque silk deposits). The same argument applies to advertisement.

All these forms of defense operate visually and it is necessary to be cautious about conclusions concerning the visual acuity of predators. One of the lessons of ethological studies is that in many situations animals actually attend to relatively simple stimuli even when they are quite capable of discriminating more complex ones. There is an excellent treatment of this subject in Hinde (1970: 57-80). Despite this qualification, we feel that a visually-operating function for the skeleton-web stabilimenta of $N$. clavipes is highly improbable.

The defensive function of reinforcing the hub against penetration by predators that strike through the web can be rejected because the silk is simply not deposited in the hub region. The structure could conceivably form a barrier to spider-hunting insects that might otherwise fly through the skeleton web and attack the spider from below. This function is improbable in view of the limited area covered by the device.

A function as an insect attractant is highly improbable, not only because the device is inconspicuous but also because the web has no viscid spiral and cannot, therefore, trap prey. (In addition, the spiders do not feed in the period immediately prior to moulting.) Web protection is probably achieved by the barrier webs and this function of the stabilimentum can be rejected for this reason. The structure is not sufficiently dense to act as an effective sunshield and, furthermore, is in the wrong place. (Note that some araneids adopt complex postures, at times, in order to minimize heat absorption, Krakauer 1972, Robinson \& Robinson 1973.)

The fact that the stabilimentum occurs most commonly in skeleton webs could be correlated with a mechanical function. The laying down of zig-zags on those radii that are immediately below the point at which the moulting spider attaches itself to the hub may stabilize this attachment. This would ensure a secure moulting base within an area protected by the barrier webs. From this base the spider could safely go through the fairly vigorous process of withdrawing from the old cuticle. The moulting process involves much pulling and jerking and if the spider loses connection with the web, and drops to the ground, the result may be fatal. The reinforcement of 
the skeleton web could also strengthen the platform on which the spider assumes its normal stance as the new cuticle hardens. If these are the mechanical functions of stabilimentum building at this stage, it is necessary to explain why this solution to the problem of building a strong moulting platform has been adopted. The omission of the viscid spiral is explicable on the grounds that if insects were trapped in a moulting platform, their struggles could dislodge the moulting spider at a critical moment. In addition, feeding seems to be inhibited at this stage and expenditure on prey-capture systems would be wasteful. (It is also possible that silk production is inhibited prior to moulting, perhaps because of the urgent biosynthetic priority of moulting itself.) If the viscid spiral is omitted, the platform could still be stabilized by the deposition of structural silk in the form of a temporary spiral. Constructing a spiral is probably a more expensive process than simply reinforcing the relevant radii by the act of 'overstitching' them with zig-zags. The latter involves only a small number of excursions from the hub region. Studies of the building of skeleton webs could provide a more detailed basis for further speculation about this problem. A function related to strengthening a moulting platform would account for the virtual restriction (see Table I) of stabilimentum building to the skeleton webs of immature Nephila clavipes.

The dense perpendicular stabilimenta found in perfect webs of Nephila maculata (and the single example from N. clavipes shown in Figure I.) could function defensively by disguise or deflection. In this case it is only necessary to assume that some predators are inhibited from attacking large spiders to explain the restriction of the devices to the webs of immatures. Thus if the stabilimentum increased the apparent size of the juvenile spider (disguise) or was itself mistaken for a small spider (deflection) it could inhibit or deflect attacks on the otherwise attack-eliciting juvenile. This explanation is plausible but unsatisfactory in view of the extreme rarity of the stabilimenta.

A mechanical function for such infrequently-built structures could only be justified if webs required additional strengthening (tensioning or bracing) on rare occasions. This is possible but we have no evidence that it is probable.

It is possible to assume that the rare phenomenon of stabilimentum building in perfect webs is an aberrant expression of a behavior that is functional in the context of the skeleton web. (We do not know whether Nephila maculata builds stabilimenta in such webs.) If this were so, the greater density of the structure could result from the 
fact that radii are separated by much shorter distances. This possibility could have interesting implications from the evolutionary standpoint (see below).

Rarity of a functional structure (and behavior) could be explained by assuming that the present state of the two species represents an early stage in the evolution of stabilimentum-building. Conversely, if the structures are regarded as presently non-functional, they could be looked on as vestigial. Although no definite conclusion is possible about the function of the stabilimenta in perfect webs, it is worth exploring the implications of these two assumptions.

If it is assumed that the behavior is vestigial, it must be concluded that it has lost its original function(s). If it is assumed that the original function was defensive, then either it is no longer an effective defense against predators or the spider has evolved more effective defenses. The first possibility could result from a change in the spectrum of predators exerting selection pressure on defensive devices or from an advance in the behavior of the predators that rendered the device ineffective. Nothing useful can be said about these two possibilities. If the spider has evolved more effective defensive adaptations these should be detectable at present. The most obvious present-day defensive devices of Nephila species are the spider's escape behavior and its barrier webs. Escape behavior is, we think, unlikely to be a recent specialization. Kaston (r964) regards the barrier webs as primitive on grounds that seem reasonably secure. We conclude that the probability that the structure is a vestigial defensive device is extremely low.

Similar arguments suggest a rejection of the hypothesis that the stabilimenta are vestigial bracing devices. Presentday Nephila spp. brace the hub regions of their webs with strong lines attached to the barrier webs. These structures are probably a primitive feature of web construction and would seem to make a bracing stabilimentum redundant.

The contrary assumption that these Nephila species are at a stage close to the origins of stabilimentum-building behavior may have greater heuristic value. As far as we know, there has been no attempt to explain the origins of ribbon stabilimenta. Since the structures are added on to structural members and are not simply additions of structural silk, any theories of derivation must take this into account.

Most (if not all) araneids use ribbon silk for a variety of purposes (see Kaston 1964). Given this faculty, the first stage in the evolution of stabilimenta could be the use of this silk to reinforce 
moulting platforms (to minimize constructional effort as suggested above). Once this behavior has evolved, lines of further variation (and selection) are possible. The step(s) to the production of a dense perpendicular band in a functional web could follow several evolutionary paths. Nephila species often renew the radii and viscid elements of one side of the web while leaving the other side untouched (see Peters 1955). This process frequently results in the formation of a perpendicular renewal line. If this renewal line were reinforced with zig-zag silk (an extension of skeleton web reinforcement behavior) a rudimentary stabilimentum could result (in a functional web). Such an origin for the perpendicular stabilimentum is at least possible. Assuming that the mechanical function of overstitching could be exploitable in further situations (other than the partial renewal of a web) the behavior would be a potential starting point for further selection.

In addition, behavior such as this, with a function originally related to the mechanisms of web renewal, might incidentally have an anti-predator effect. A conspicuous junction line might be marginally concealing, deflecting, advertising or disguising. Selection exerted by predators on further variations in this behavior might then result in transformation of the structure and function of the device. This means that stabilimenta could have evolved under different selection pressures to fulfill different functions in different species of spiders. This view seems to us to be at least as probable as the assumption that all stabilimenta have a common function.

\section{Summary}

I. The stabilimenta built by Nephila clavipes (and N. maculata) are characterized by being laid down as zig-zags of ribbon silk between adjacent radii.

2. Such devices are rare in complete webs but relatively common in the skeleton webs of immature $N$. clavipes that are built as moulting platforms. The situation with regard to skeleton webs built by $N$. maculata is not known.

3. A functional explanation of the stabilimenta built into such skeleton webs is that they reinforce an otherwise reduced, simplified and possibly unstable structure. A secure base for moulting is regarded as essential to the development of the spider.

4. Defensive or other non-mechanical functions for the stabilimenta in skeleton webs are, we think, highly improbable.

5. Perpendicular stabilimenta in complete Nephila webs are so rare as to make functional explanation difficult. 
6. The hypothesis that Nephila stabilimenta are vestigial seems to be largely untenable.

7. We suggest that the devices built into skeleton webs could represent a primitive stage of stabilimentum construction. Hypothetical steps leading from this stage to the evolution of the perpendicular stabilimentum could include one at which zig-zag 'overstitching' was used to reinforce a line of junction between old and new sections of a partially renewed web. The further evolution of stabilimenta from this stage could have followed different functional pathways in different species.

\section{REFERENCES}

Bonnet, P.

1958. Bibliographia Araneorum Vol. II. N-S. Douladore, Toulouse.

EWER, R. F.

1972. The devices in the web of the West African spider Argiope

Hinde. R. A.

flavipalpis. J. nat. Hist.,6: 159-167.

1970. Animal Behaviour. McGraw Hill Book Co. N.Y. 2nd ed.

KAstoN, B. J.

1964. The evolution of spider webs. Amer. Zool., 4: 191-207.

KrakaUer, $T$.

1972. Thermal responses of the orb-weaving spider Nephila clavipes (Araneae: Argiopidae). Am. Midl. Nat., 88: 245-250.

Marples, B. J.

1969. Observations on decorated webs. Bull. Br. Arachnological Soc., 1: 13-18.

Peters, H. M.

1953. Beiträge zur Vergleichenden Ethologie und Ökologie Tropischer Webenspinnen. Z. Morph. Ökol. Tiere., 42: 278-306.

1954. Estudios adicionales sobre la estructura de la red concentrica de las arañas. Comun. Inst. Trop. El Salvador, 1: 1-18.

1955. Contribuciones sobre la etologia y ecologia comparada de las arañas tejedoras tropicales. Comun. Inst. Trop. El Salvador, 1-2: $37-46$.

Robinson, M. H. \& B. Robinson.

1970. The stabilimentum of the orb web spider, Argiope argentata: an improbable defence against predators. Can. Ent., 102: 641-655.

1973. The ecology and behavior of the giant wood spider Nephila

SIMON, E. maculata (Fabricius) in New Guinea. Smith. cont. Zool., 149: 1-76.

1892-1895. Histoire naturelle des Araignées. Roret, Paris. 

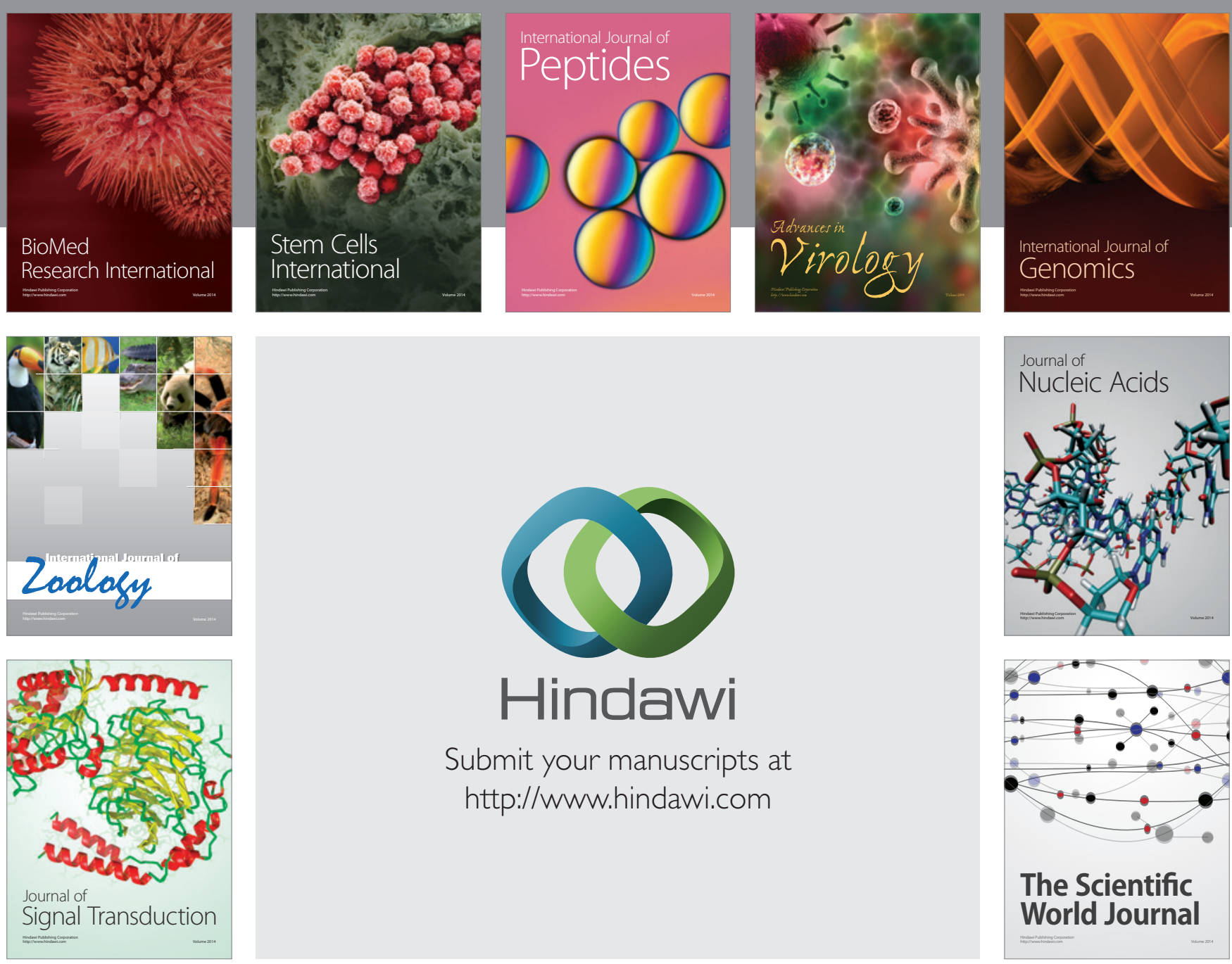

Submit your manuscripts at

http://www.hindawi.com
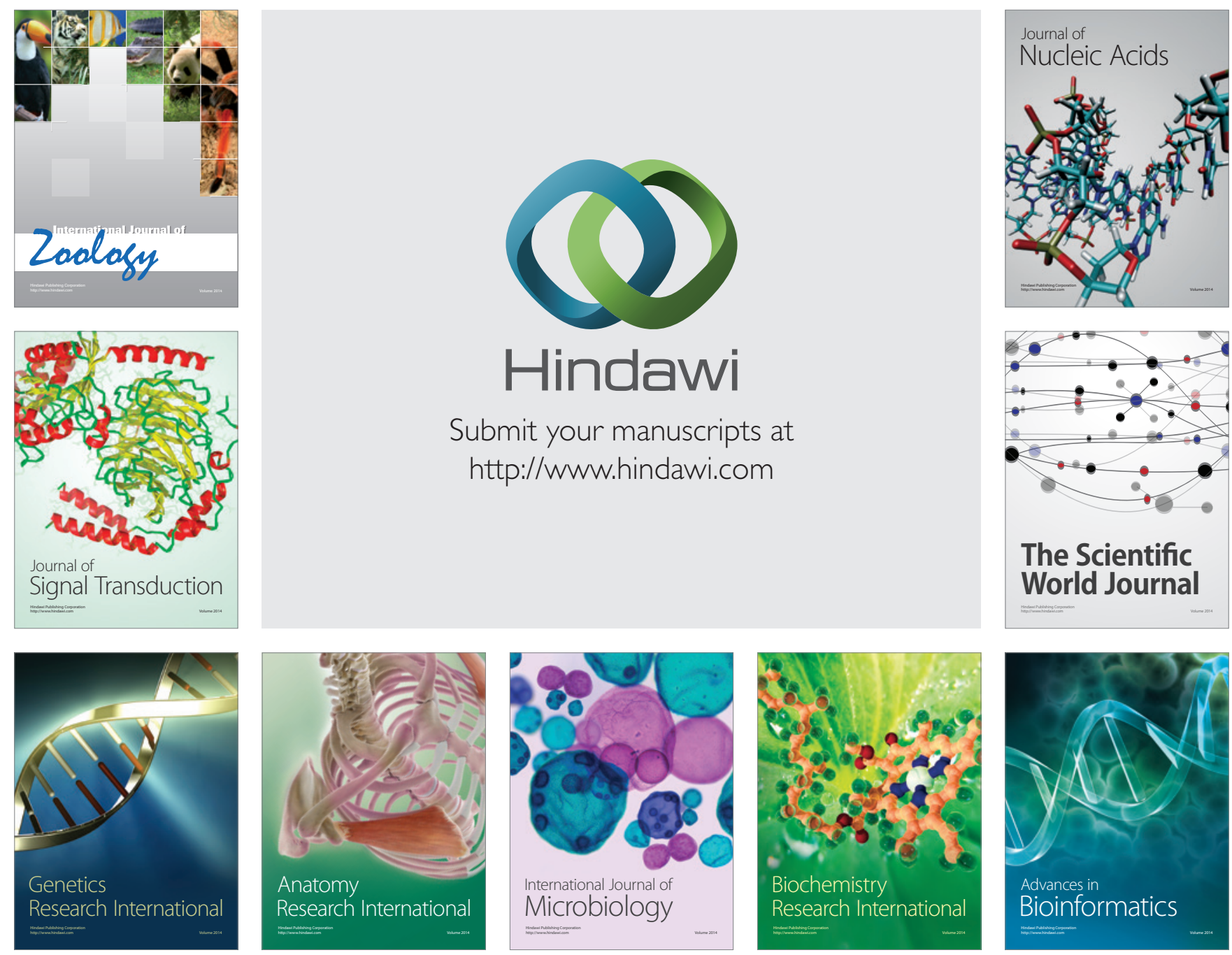

The Scientific World Journal
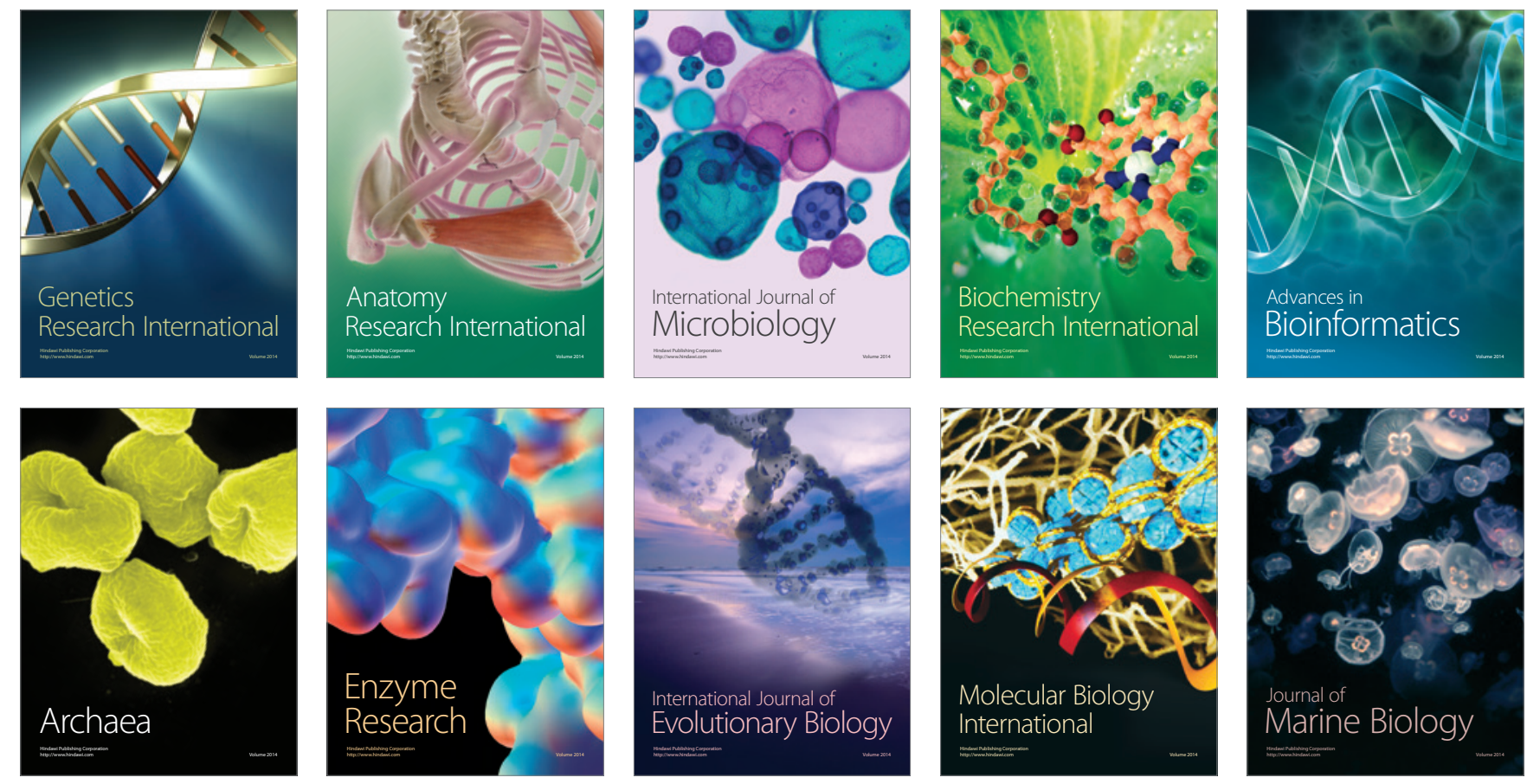